\title{
Barrel Dosing Unit
}

National Cancer Institute

\section{Source}

National Cancer Institute. Barrel Dosing Unit. NCI Thesaurus. Code C149350.

A unit of presentation used to represent the quantity of product that is found in a single barrel container. 